\title{
PERANAN PROMOSI DALAM MENINGKATKAN VOLUME PENJUALAN KERAMIK GARUDA PT. GARUDA MAKMUR SENTOSA PEMATANGSIANTAR
}

\author{
Oleh: \\ Natalia \\ S1 Manajemen \\ Darwin Lie, Marisi Butarbutar, Efendi
}

Abstraksi

PT. Garuda Makmur Sentosa Pematangsiantar adalah perusahaan yang bergerak dibidang penjualan keramik merek Garuda. Dalam memasarkan produknya, PT. Garuda Makmur Sentosa Pematangsiantar mengalami kesulitan karena adanya persaingan yang ketat dengan merek keramik lainnya. Maka untuk menghadapi persaingan, PT. Garuda Makmur Sentosa Pematangsiantar melakukan berbagai kegiatan promosi kepada konsumen agar konsumen dapat mengenal keramik merek Garuda. Kegiatan promosi yang dilakukan adalah melalui iklan yang dilakukan lewat media radio dan surat kabar. Selain itu juga PT. Garuda Makmur Sentosa Pematangsiantar melakukan kegiatan promosi penjualan yaitu dengan cara membagikan contoh produk gratis dan memberikan potongan harga kepada konsumen dan toko langganan yang membeli keramik Garuda baik dalam jumlah yang besar maupun jumlah yang kecil.

Penulis menggunakan dua metode penelitian yaitu penelitan lapangan dan penelitan kepustakaan.metode pengumpulan data dengan observasi, wawancara dan dokumentasi yang bersumber dari data primer dan skunder dan dianalisa dengan analisa deskriptif dan komparatif.

Kesimpulan dari penelitian ini adalah promosi berperan dalam meningkatkan volume penjualan keramik Garuda. Hasil tersebut dinyatakan dalam hasil perhitungan analisis trend yaitu $Y^{\prime}=43.859,16+282,08 X$ yang artinya bahwa promosi berbanding positip dalam meningkatkan volume penjualan keramik Garuda. Adapun saran dalam penelitian ini adalah Dalam upaya untuk meningkatkan volume penjualan keramik Garuda PT. Garuda Makmur Sentosa Pematangsiantar dimasa mendatang, diharapkan dapat meningkatkan biaya promosinya melalui mencetak brosur dan katalog yang dapat dibagikan kepada konsumen dan membagikan sampel produk baru gratis secara merata dan tepat waktu kepada toko langganan.

Kata kunci : Promosi dan Penjualan

\section{Abstract}

PT. Garuda Makmur Sentosa Pematangsiantar is a company engaged in selling brand Garuda ceramic. In marketing its products, PT. Garuda Makmur Sentosa Pematangsiantar experien difficulties because of the tight competition with other ceramic brands. But for competition, PT. Garuda Makmur Sentosa Pematangsiantar doing various promotional activities to consumers so that consumers can identify brand Garuda ceramic. Promotional activities undertaken is done through advertisements in the mass media of radio and newspapers. Moreover, we PT. Garuda Makmur Sentosa Pematangsiantar do sales promotion activities in a way that is distribute free product samples and give discounts to consumers who buy a subscription and ceramics shop Garuda good in large amounts or small amounts.

Authors used two methods of fieldwork research and library research. Methods of collection data through observation, interviews and documentation are derived from primary and secondary data source and analyzed with descriptive and comparative analysis .

The conclusion of this study is the promotion of a role in increasing the sales volume of Garuda ceramic. Results are expressed in the calculation of the trend analysis $Y^{\prime}=43.859,16+282,08 X$, which means that the promotion of positive value in increasing the sales volume of Garuda ceramic. The advice in this study is in an effort to increase ceramic sales volume, PT Garuda Makmur Sentosa Pematangsiantar future is expected to increase the cost of promotion through print catalogs and brochures that can be distributed to consumers and distribute free samples of new products and timely evenly to store subscriptions.

Keywords: Promotion and Sales

\section{A. PENDAHULUAN}

1. Latar Belakang Masalah

PT. Garuda Makmur Sentosa

Pematangsiantar yang merupakan salah satu perusahaan yang bergerak dibidang penjualan keramik merek Garuda. PT. Garuda Makmur Sentosa Pematangsiantar juga selalu berusaha untuk terus mempertahankan tingkat volume penjualan keramik Garuda walaupun mengalami kesulitan dalam memasarkan produknya. Tingkat volume 
penjualan keramik Garuda PT. Garuda Makmur Sentosa mengalami kenaikan dan penurunan setiap bulannya. Hal ini terlihat pada semester pertama terjadi kenaikan dalam setiap bulannya. Pada semester kedua jumlah penjualan setiap bulannya terjadi kenaikan dan penurunan yang tidak stabil. Demikian juga dengan penjualan pada semestersemester berikutnya. Kenaikan dan penurunan volume penjualan keramik Garuda ini disebabkan oleh adanya persaingan dengan merek keramik lainnya seperti Roman, Platinum, Arwana, dan merek-merek keramik lainnya yang telah lebih dikenal oleh masyarakat.

Dalam menghadapi persaingan tersebut, PT. Garuda Makmur Sentosa melakukan berbagai usaha untuk mempertahankan tingkat volume penjualannya yaitu dengan melakukan kegiatan promosi dengan mengunakan jasa iklan yaitu melalui radio dan surat kabar yang bertujuan untuk menarik minat masyarakat agar berkeinginan membeli keramik Garuda yang ditawarkan. Selain itu, PT. Garuda Makmur Sentosa juga menggunakan promosi penjualan yaitu dengan memberikan potongan harga kepada konsumen yang membeli keramik Garuda baik dalam jumlah yang besar maupun jumlah kecil serta memberikan contoh produk keramik kepada toko-toko langganan. Hal ini dilakukan oleh PT. Garuda Makmur Sentosa Pematangsiantar untuk meningkatkan jumlah konsumen terhadap perkembangan produk keramik Garuda yang ditawarkan oleh perusahaan.

\section{Rumusan Masalah}

Berdasarkan latar belakang masalah di atas, yang menjadi rumusan masalah adalah :

a. Bagaimana kegiatan promosi yang dilakukan untuk meningkatkan volume penjualan keramik Garuda pada PT. Garuda Makmur Sentosa Pematangsiantar?

b. Bagaimana peranan promosi yang dilakukan untuk meningkatkan volume penjualan keramik Garuda pada PT. Garuda Makmur Sentosa Pematangsiantar?

\section{Tujuan Penelitian}

Adapun tujuan penelitian ini adalah :

a. Untuk mengetahui kegiatan promosi yang dilakukan untuk meningkatkan volume penjulaan keramik Garuda pada PT. Garuda Makmur Sentosa Pematangsiantar.

b. Untuk mengetahui peranan kegiatan promosi dalam meningkatkan volume penjualan keramik Garuda pada PT. Garuda Makmur Sentosa Pematangsiantar.

\section{Metode Penelitian}

Dalam penelitian ini, menggunakan metode kepustakaan dan lapangan. Jenis data kualitatif dan kuantitatif, dengan metode pengumpulan data dengan observasi, wawancara dan dokumentasi yang bersumber dari data primer dan skunder dan dianalisa dengan analisa deskriptif dan komparatif.

\section{B. LANDASAN TEORI}

\section{Promosi}

Menurut Machfoedz (2007:122), promosi merupakan suatu upaya yang dilakukan oleh perantara pemasar untuk mempengaruhi pihak lain agar turut berpartisipasi dalam perubahan yang mereka lakukan. Menurut Boyd (2000:65), promosi adalah upaya membujuk orang untuk menerima produk, konsep, dan gagasan. Sedangkan menurut Alma (2002:135), promosi adalah sejenis komunikasi yang memberi penjelasan yang menjelaskan calon konsumen tentang barang dan jasa.

Menurut Shimp (2000:7), promosi memiliki lima fungsi yaitu :

a. Memberikan informasi

b. Membujuk

c. Mengingatkan

d. Menambah nilai

e. Mendampingi upaya-upaya lain dari perusahaan

Menurut Kotler dan Armstrong (2009:137), bauran promosi adalah perusahaan diindustri yang sama bisa menggunakan bauran promosi yang berbeda. Sedangkan menurut Stanton dalam Husein (2008:8), bauran promosi adalah kombinasi strategi yang paling baik dari variabel-variabel periklanan, penjualan pribadi, dan alat promosi lainnya yang kesemuanya direncanakan untuk mencapai tujuan program penjualan.

Menurut Tjiptono (2008:222), bauran promosi terdiri atas:

1) Penjualan pribadi

2) Mass Selling

3) Promosi Penjualan

4) Hubungan Masyarakat

5) Direct Marketing

Menurut Machfoedz (2007:122), iklan adalah segala bentuk penyajian informasi dan promosi secara tidak langsung yang dilakukan oleh sponsor untuk menawarkan ide, barang, atau jasa. Menurut Kotler (2005:74), periklanan adalah bagian keputusan yang kompleks dan lingkungan makro yang berubah membuatnya semakin rumit.

Menurut Machfoedz (2007:122), iklan memiliki fungsi antara lain:

a) Fungsi pemasaran

b) Fungsi komunikasi

c) Fungsi ekonomis

d) Fungsi sosial

Menurut Kotler (2007:266), promosi penjualan adalah berbagai kumpulan alat-alat insentif yang sebagian besar berjangka pendek, yang dirancang untuk memasang pembelian produk atau jasa tertentu dengan lebih cepat dan lebih besar oleh konsumen atau pedagang.

Menurut Alma (2002:145), tujuan digunakan promosi penjualan antara lain:

1) Menarik para pembeli baru.

2) Memberi hadiah/penghargaan kepada konsumen atau pelanggan lama. 
3) Meningkatkan daya pembelian ulang dari konsumen lama.

4) Menghindarkan konsumen lari ke merek lain.

5) Mempopulerkan merek/meningkatkan loyalitas.

6) Meningkatkan volume penjualan jangka pendek dalam rangka memperluas "market share" jangka panjang.

\section{Penjualan}

Menurut Kartajaya (2010:2), penjualan adalah sebuah proses yang memiliki tahapan yang menuntut keterampilan yang berbeda. Menurut Swasta dalam Yasin (2009:6), penjualan adalah ilmu dan seni mempengaruhi pribadi yang dilakukan oleh penjual untuk mengajak orang lain agar bersedia membeli barang atau jasa yang ditawarkan.

Menurut Swasta dalam Yasin (2009:6), faktor-faktor yang mempengaruhi penjualan yaitu:

a. Kondisi dan kemampuan penjual

b. Kondisi pasar

c. Modal

d. Kondisi organisasi perusahaan

e. Faktor lain

\section{PEMBAHASAN}

\section{Analisa}

PT. Garuda Makmur Sentosa Pematangsiantar menggunakan iklan dan promosi penjualan untuk memperkenalkan keramik Garuda kepada masyarakat. Iklan yang digunakan dalam memasarkan keramik Garuda dilakukan lewat media surat kabar yaitu surat kabar harian Analisa yang digunakan sejak bulan September 2010 hingga Agustus 2011 dan juga melalui siaran radio melalui siaran radio Boss FM Pematangsiantar yang digunakan pada bulan September 2011.

Selain melalui media iklan, PT. Garuda Makmur Sentosa juga melakukan promosi penjualan yaitu dengan memberikan potongan harga berupa potongan tunai kepada konsumen baik itu konsumen yang membeli secara langsung ataupun toko-toko pelanggan. Kriteria pemberian potongan tunai ini adalah apabila konsumen dan toko-toko langganan datang sendiri mengambil keramik Garuda dari gudang PT. Garuda Makmur Sentosa Pematangsiantar. Apabila keramik Garuda yang dibeli diantar menggunakan mobil PT. Garuda Makmur Sentosa maka tidak akan mendapat potongan tunai. Selain itu juga membagikan contoh produk gratis kepada toko-toko langganan untuk mempermudah konsumen mengetahui corak keramik Garuda yang ditawarkan.

Dalam menetapkan promosi melalui iklan dan promosi penjualan, maka PT. Garuda Makmur Sentosa Pematangsiantar menetapkan anggaran biaya promosi untuk mengetahui berapa besar biaya yang dibutuhkan perusahaan untuk mencapai sasaran yang telah ditetapkan yaitu meningkatkan volume penjualan. Adapun data biaya promosi yang dilakukan oleh PT. Garuda Makmur Sentosa Pematangsiantar mulai dari September 2010 sampai dengan agustus 2012 disajikan dalam tabel berikut:
Tabel 1

Biaya Promosi (dalam jutaan)

\begin{tabular}{|c|c|c|c|c|}
\hline \multirow{2}{*}{ Pro ScmetrT } & \multicolumn{2}{|c|}{ 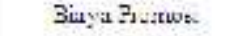 } & \multirow{2}{*}{$\begin{array}{l}\text {-nta } \\
\text { Bikva } \\
\therefore \text { stuos. }\end{array}$} & \multirow{2}{*}{ ?aretulat } \\
\hline & Tklan & $\begin{array}{l}\text { Promok: } \\
\text { Pexjualan }\end{array}$ & & \\
\hline Stp'-0.5:t'11 & $2 \mathrm{p}=2,5$ & $\mathrm{E}_{\mathrm{p}} \mathrm{ICC}+3$ & DF 122,83 & $100 \% 6$ \\
\hline 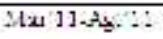 & E.p 24,2 & Ep11332 & Epl3sL & $2: 2.34 \%$ \\
\hline Sep $: 1-1=t \cdot 12$ & L 24.33 & Hp 121,20 & D.F 14 Sis & $: 21.9: 1 /=$ \\
\hline 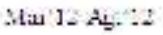 & $\operatorname{sp} 32.7$ & Kp 12282 & $\mathrm{Kp}$ los & $228.93 \%$ \\
\hline
\end{tabular}

Sumber: PT. Garuda Makmur Sentosa

Pematangsiantar

Berdasarkan tabel diatas, maka dapat dilihat peningkatan biaya promosi yang dilakukan oleh PT. Garuda Makmur Sentosa Pematangsiantar pada semester I (September 2010 - Februari 2011) adalah sebesar Rp. 122.930.000,- dengan tingkat persentase sebesar 100\%. Pada semester II (Maret 2011 Agustus 2011) biaya promosi mengalami kenaikan yaitu sebesar 12,34\%. Peningkatan ini disebabkan karena PT. Garuda Makmur Sentosa meningkatkan promosi penjualan yaitu dengan cara memberikan potongan tunai kepada konsumen yang membeli keramik Garuda.

Pada semester III (September 2011 Februari 2012), biaya promosi yang dilakukan PT. Garuda Makmur Sentosa Pematangsiantar mengalami kenaikan sebesar 21,90\%. Hal ini disebabkan karena Promosi yang dilakukan pada semester III ini lebih besar bila dibandingkan dengan semester II. Hal ini disebabkan karena PT. Garuda Makmur Sentosa melakukan promosi produk baru kepada konsumen dengan cara mencetak katalog yang berisikan perincian produk baru keramik Garuda yang ditawarkan oleh PT. Garuda Makmur Sentosa Pematangsiantar. Pada semester IV (Maret 2012 - Agustus 2012), biaya promosi yang dilakukan PT. Garuda Makmur Sentosa Pematangsiantar mengalami peningkatan sebesar 28,93\%. Hal ini disebabkan karena Promosi yang dilakukan pada semester IV ini meningkat sedikit bila dibandingkan dengan semester sebelumnya. Hal ini disebabkan karena PT. Garuda Makmur Sentosa melanjutkan penawaran produk baru kepada konsumen sehingga konsumen mengetahui bahwa PT. Garuda Makmur Sentosa menawarkan keramik dengan ukuran dan corak yang baru yang sesuai dengan kebutuhan pasar sekarang ini. Selain data jumlah biaya, juga sudah dikumpulkan data-data dari penjualan keramik garuda. Berikut ditampilkan data tabel volume penjualan :

Tabel 2

Volume Penjualan

\begin{tabular}{|c|c|c|}
\hline Bulan & $\begin{array}{c}\text { Volume } \\
\text { Penjualan }\end{array}$ & $\begin{array}{c}\text { Persentase } \\
(\boldsymbol{\%})\end{array}$ \\
\hline Sep'10-Feb'11 & 78.728 Kotak & $100 \%$ \\
\hline Mar'11-Agt'11 & 82.294 Kotak & $104,53 \%$ \\
\hline Sept'11-Feb'12 & 86.574 Kotak & $109,97 \%$ \\
\hline Mar'12-Agt'12 & 88.457 Kotak & $112,36 \%$ \\
\hline Total & 336.053 Kotak & \\
\hline
\end{tabular}

Sumber: PT. Garuda Makmur Sentosa

Pematangsiantar 
Berdasarkan tabel volume penjualan diatas, dapat dilihat bahwa penjualan keramik Garuda PT. Garuda Makmur Sentosa Pematangsiantar pada semester I adalah sebesar 78.728 kotak. Pada semester II, penjualan keramik Garuda mengalami kenaikan sebesar $4,53 \%$ dari penjualan semester 1 . Pada semester III, penjualan keramik Garuda juga mengalami kenaiakan persentase penjualan yaitu sebesar 9,97\%. Hal ini membuktikan bahwa promosi yang dilakukan oleh PT. Garuda Makmur Sentosa Pematangsiantar adalah berhasil. Pada semester IV, persentase penjualan keramik Garuda juga mengalami kenaikan dari semester sebelumnya yaitu sebesar $12,36 \%$.

Bardasarkan data kedua tabel diatas, dapat dicari peranan promosi terhadap penjualan melalui metode analisis trend dan diperoleh hasil $Y^{\prime}=43.859,16+282,08 \mathrm{X}$ yang artinya bahwa promosi berbanding positip dalam meningkatkan penjualan keramik Garuda PT. Garuda Makmur Sentosa Pematangsiantar.

\section{Evaluasi}

Dalam rangka untuk mencapai tujuan perusahaan yaitu meningkatkan volume penjualan untuk memperoleh laba yang sebesar-besarnya dan untuk mengatasi persaingan dengan perusahaan lain yang sejenis, maka PT. Garuda Makmur Sentosa Pematangsiantar melakukan kebijakan promosi yaitu sebagai berikut:

a. Periklanan

Dengan periklanan, perusahaan diharapkan dapat membangun citra produk dalam jangka waktu yang panjang. Umumnya, periklanan merupakan semua kegiatan yang dilakukan dalam menawarkan produk kepada masyarakat atau konsumen baik secara lisan maupun secara tulisan.

Dalam membuat iklan, perusahaan dapat membuat keputusan dalam periklanan yaitu:

1) Mencetak Kalender

Yaitu mencetak kalender yang mencantum nama perusahaan, alamat, nomor telepon dan gambar dari jenis-jenis produk yang ditawarkan perusahaan diakhir tahun dan membagikannya kepada konsumen, toko-toko langganan yang ada dikota Pematangsiantar. Hal ini dilakukan agar, masyarakat atau konsumen mengenal keramik Garuda yang ditawarkan oleh PT. Garuda Makmur Sentosa Pematangsiantar.

\section{2) Kartu Nama}

Kartu nama dicetak untuk dibagikan kepada konsumen maupun kepada toko-toko langganan yang membeli keramik Garuda dari PT. Garuda Makmur Sentosa. Kartu nama ini dilengkapi dengan alamat dan nomor telepon PT. Garuda Makmur Sentosa Pematangsiantar agar konsumen dan toko-toko langganan lebih mudah mengetahui informasi lokasi gudang PT. Garuda Makmur Sentosa dan untuk mengetahui tentang produk-produk yang tersedia dalam gudang PT. Garuda Makmur Sentosa sehingga konsumen tidak bingung untuk mencari tahu keberadaan produk keramik yang diinginkan.

3) Katalog

Katalog dicetak untuk dibagikan kepada toko-toko langganan yang membeli keramik Garuda dari PT. Garuda Makmur Sentosa Pematangsiantar. Katalog ini dilengkapi dengan gambar dan ukuran keramik yang ditawarkan oleh perusahaan sehingga toko-toko langganan dapat lebih mudah mengetahui informasi akan produk yang tersedia.

b. Promosi Penjualan

PT. Garuda Makmur Sentosa membagikan contoh produk gratis kepada toko-toko langganan sehingga akan mempermudah konsumen untuk mengetahui corak keramik yang ditawarkan oleh PT. Garuda Makmur Sentosa Pematangsiantar. Selain itu, PT. Garuda Makmur Sentosa Pematangsiantar juga memberikan potongan harga kepada konsumen dan toko-toko langganan yang membeli keramik Garuda baik yang membeli dalam jumlah kecil maupun dalam jumlah yang besar dengan cara memotong langsung total harga keramik Garuda yang harus dibayar oleh konsumen. Kegiatan ini dilakukan PT. Garuda Makmur Sentosa Pematangsiantar agar konsumen selalu mengingat akan keramik Garuda dan terus melakukan pembelian akan keramik Garuda.

\section{KESIMPULAN DAN SARAN 1. Kesimpulan}

Adapun kesimpulan yang dapat diambil adalah sebagai berikut:

a. Kegiatan promosi yang dilakukan oleh PT. Garuda Makmur Sentosa Pematangsiantar dalam memasarkan keramik Garuda adalah dalam bentuk iklan dan promosi penjualan. Media iklan yang digunakan dalam memasarkan keramik Garuda adalah melalui media surat kabar dan siaran radio. Sedangkan dalam promosi penjualan, PT. Garuda Makmur Sentosa Pematangsiantar memberikan potongan harga berupa potongan tunai kepada konsumen dan membagikan contoh produk gratis kepada tokotoko langganan.

b. Berdasarkan data biaya promosi yang dilakukan PT. Garuda Makmur Sentosa Pematangsiantar untuk memperkenalkan keramik Garuda kepada konsumen, biaya promosi yang digunakan mengalami peningkatan selama 4 (empat) semester. Peningkatan yang lebih tinggi terjadi pada semester keempat. Hal ini disebabkan karena pada semester keempat, PT. Garuda Makmur Sentosa Pematangsiantar melanjutkan penawaran produk baru kepada konsumen.

c. Berdasarkan hasil analisa yang telah dilakukan, terlihat bahwa volume penjualan keramik Garuda mengalami peningkatan setiap semesternya. Hasil tersebut dinyatakan dalam hasil perhitungan analisis trend yaitu $Y^{\prime}=43.859,16$ $+282,08 \mathrm{X}$ yang artinya bahwa promosi berbanding positip dalam meningkatkan volume 
d. penjualan keramik Garuda pada PT. Garuda Makmur Sentosa Pematangsiantar, dimana dalam setiap pertambahan 1 (satu) satuan biaya iklan dan biaya promosi penjualan akan mengakibatkan pertambahan penjualan sebanyak 282,08 kali.

\section{Saran}

Adapun saran yang dapat diberikan adalah sebagai berikut:

a. Untuk meningkatkan volume penjualan keramik Garuda PT. Garuda Makmur Sentosa Pematangsiantar dimasa mendatang, PT. Garuda Makmur Sentosa Pematangsiantar perlu meningkatkan kegiatan promosi yang telah dilakukan sebelumnya yaitu dengan cara mencetak brosur yang dapat dibagikan kepada masyarakat sehingga dapat menjangkau masyarakat yang lebih luas dan juga membuat katalog yang berisikan perincian produk-produk baru keramik Garuda yang dibagikan kepada toko-toko langganan.

b. Dalam promosi penjualan, PT. Garuda Makmur Sentosa Pematangsiantar hendaknya dapat membagikan contoh produk baru secara rutin kepada toko-toko langganan dan membagikannya secara merata kepada semua toko baik itu toko-toko besar maupun toko-toko kecil.

\section{E. DAFTAR PUSTAKA}

Alma, Buchari, 2002, Manajemen Pemasaran dan Pemasaran Jasa, Edisi Kelima, Bandung : Alfabeta.

Boyd, et. al., 2000, Manajemen Pemasaran: Suatu Pendekatan Strategis dengan Orientasi Global, Jakarta : Erlangga.

Husein, 2008, www.Huseinblog.Blogspot.com, diakses tahun 2012.

Kartajaya, Hermawan, 2010, The Official MIM Academy Coursebook Sales Operation, Jakarta : Esensi.

Kotler, Philip, 2007, Manajemen Pemasaran, Edisi Keduabelas, Jakarta : PT. Indeks.

Kotler, Philip \& Armstrong, Gary, 2009, Prinsipprinsip Pemasaran, Jilid 1\&2, Jakarta : Erlangga.

Machfoedz, Mahmud, 2007, Pengantar Bisnis Modren, Yogyakarta : Penerbit Andi.

Shimp, Terence, A, 2000, Periklanan Promosi, Aspek Tambahan Komunikasi Pemasaran Terpadu, Edisi Kelima, Jakarta : Erlangga.

Tjiptono, Fandy, 2008, Strategi Pemasaran, Edisi Ketiga, Yogyakarta : Penerbit Andi.

Yasin, Sanjaya, 2009, www.Sarjanaku.com, 2012. 